\title{
SISTEM KERJA SAMA TRAVEL AGENT PENJOR BALI DENGAN KEBERADAAN GEKKO THE OCEAN CAFÉ DI PANTAI KEDONGANAN KECAMATAN KUTA SELATAN KABUPATEN BADUNG
}

\author{
I Putu Agus Darmawan \\ I Ketut Suwena \\ Ni Putu Eka Mahadewi \\ E-mail : darmawana31@gmail.com \\ PS. S1 Industri Perjalanan Wisata \\ Fakultas Pariwisata UNUD
}

\begin{abstract}
To develop café industry in Kedonganan, café managers work together with Travel Agent to maintain café industry. One of cooperation is conducted in collaboration with Travel Agent, because it has been known that Kedonganan Café is one of the including culinary destinations for the package of Travel Agent.

Data collection technique use observation, in-depth interviews, and library research. Type of data used is quantitative data and qualitative data. Data sources use primary data and secondary data. Data analysis method is descriptive qualitative analysis using the SWOT.

Results of discussions conducted with SWOT that SO strategy is a strategy to increase cooperation with the Travel Agent, WO strategy is a strategy of delivering the best service and increase promotion, ST strategy is a strategy for cooperation contract agreements so that there are rules that bind both parties, WT strategy is a strategy to maintain and seafood prices set by mutual agreement so that the entire café manager harmonious relationship between fellow managers. The suggestion in this paper is in the doing that the agreement has been agreed to include regulations that govern both parties, preferably whole café manager called a meeting together to set prices and package alacarte seafood for Travel Agent.
\end{abstract}

Keyword : Café Industry, Cooperation System, Strategy.

\section{PENDAHULUAN}

Salah satu pantai yang menjadi daerah wisata yang selalu dikunjungi yaitu pantai Kedonganan. Pantai Kedonganan terletak di Desa Kedonganan Kecamatan Kuta Selatan Badung Bali, Pantai Kedonganan memiliki syarat-syarat untuk menjadi daerah tujuan wisata. selain keindahan pantai pasir putihnya, pantai Kedonganan memiliki potensi sebagai daerah tujuan wisata kuliner. Cafe Seafood merupakan sarana yang menjadikan daerah Kedonganan menjadi tempat yang sangat komplit untuk dikunjungi. Terdapat 24 café yang tersedia di sepanjang pesisir pantai Kedonganan dan menyajikan masakan seafood sebagai menu utamanya. Apalagi di pantai Kedonganan, wisatawan dapat menikmati keindahan sunset, tebing uluwatu dari kejauhan serta dari pantai Kedonganan wisatawan dapat menikmati keindahan pesawat yang mendarat ke Bali melalui landasan run way yang dapat dilihat langsung dari pantai.

Untuk lebih meningkatkan kunjungan wisatawan yang datang ke cafe Kedonganan, maka pihak manajemen cafe perlu melakukan suatu kerja sama kepada pihak-pihak yang tentunya dapat mendatangkan tamu untuk lebih meningkatkan pendapatan yang masuk ke cafe Kedonganan. Salah satunya yaitu melakukan kerja sama dengan Travel Agent. Dengan melakukan kerja sama dengan travel 
agent, café Kedonganan mendapatkan beberapa manfaat yaitu sealin meningkatkan pendapatan, manfaat lainnya yaitu bisa dijadikan promosi kepada tamu yang berkunjung agar datang kembali bersama keluarga mereka. Jadi disini penulis ingin menjelaskan mengenai sistem kerja sama yang dilakukan antara Gekko The Ocean café Kedonganan dengan travel agent yang menggunakan analisis SWOT.

\section{METODE PENELITIAN}

Penelitian ini dilakukan di Gekko The Ocean Cafe di Pantai Kedonganan. Adapun kajian pustaka yang digunakan di dalam penelitian yaitu dari Jogianto (2005) dengan tinjauan tentang pengertian sistem, dari Davis (2006) dengan tinjauan tentang kerja sama, dari Sihite (2000) dengan tinjauan tentang biro perjalanan dan dari Suarthana (2006) dengan tinjauan tentang restoran.

Pengumpulan data dari penelitian ini dilakukan dengan cara observasi, wawancara secara terstruktur, dan studi kepustakaan. Penelitian ini merupakan penelitian kualitatif deskriptif yang hanya berbentuk suatu penjelasan yang menggambarkan keadaan, proses atau peristiwa tertentu. Teknik analisis yang digunakan adalah teknik analisis SWOT yang berfokus pada sistem kerja sama antara Cafe Kedonganan dengan travel agent dalam menaikkan jumlah kunjungan tamu ke pantai Kedonganan.

\section{HASIL DAN PEMBAHASAN}

Gekko The Ocean Café berlokasi di Desa Kedonganan daerah Pantai Kedonganan. Café Kedonganan sudah berdiri sekitar tahun 2007 oleh Desa Adat setempat. Sampai saat ini jumlah Café di Kedonganan dulunya berjumlah 53 Café dan sudah diciutkan menjadi 24 Cafe. Dalam pengelolaannya, café di Kedonganan dikelola oleh Desa adat setempat dan dimiliki juga oleh desa adat. Jadi semua café di Kedonganan dimiliki oleh masyarakat desa dan ini sangat membantu masyarakat desa dalam sektor perekonomian.

Dari segi manfaatnya kerja sama yang dilakukan sangat oleh pihak café Kedonganan dengan Travel Agent sangat besar dan menguntungkan semua pihak yang terlibat. Dari pihak café sendiri akan mendapatkan penjualan yang menigkat dengan kedatangan tamu yang didatangkan oleh Travel Agent. Sedangkan, dari pihak Travel Agent mereka akan mendapatkan keuntungan dari harga paket karena telah membawa tamu ke Café Kedonganan

Dalam penelitian ini digunakan analisis deskriptif kualitatif yang menjelaskan gambaran yang disusun secara sistematis, aktual dan akurat sesuai dengan fakta yang ada. Pada prinsipnya data kualitatif lebih cenderung menguraikan secara lengkap dan terperinci mengenai keadaan atau status dari objek yang diteliti melalui kata - kata atau kalimat

Analisis yang digunakan dalam penelitian ini adalah melalui pendekatan SWOT. Analisis SWOT dapat diterapkan dengan cara menganalisis dan memilah berbagai hal yang mempengaruhi keempat faktornya, kemudian menerapkannya dalam gambar matrik SWOT, dimana aplikasinya adalah bagaimana kekuatan (strengths) mampu mengambil keuntungan (advantage) dari peluang (opportunities) yang ada, bagaimana cara mengatasi kelemahan (weaknesses) yang mencegah keuntungan (advantage) dari peluang. (opportunities) yang ada, selanjutnya bagaimana kekuatan (strengths) mampu menghadapi ancaman (threats) yang ada, dan terakhir adalah bagimana cara mengatasi kelemahan (weaknesses) yang mampu membuat ancaman (threats) menjadi nyata atau menciptakan sebuah ancaman baru. Adapun hasil penelitian dengan menggunakan analisis SWOT yaitu :

1. Strengths ( kekuatan )

Dari kerja sama yang dilakukan antara Gekko The Ocean Café dengan semua Travel Agent memiliki kekuatan, yaitu :

a) Adanya tujuan yang sama antara kedua belah pihak yaitu sama - sama ingin memberikan pelayanan yang baik melalui makanan seafood.

b) Pantai Kedonganan yang terkenal dengan café seafoodnya jadi wisatawan atau tamu dengan mudah diajak untuk ke Kedonganan 
c) Pelayanan yang diberikan kepada tamu sangat maksimal demi kepuasan wisatawan

d) Promosi yang sangat banyak dilakukan

e) Akses yang sangat mudah menuju ke Pantai Kedonganan

2. Weakness ( kelemahan )

Pastinya di dalam kerja sama ini terdapat kelemahan yang melanda. Kelemahan yang biasanya datang yaitu :

a) Terjadinya complain dari tamu mengenai produk ataupun jasa yang menyebabkan pihak Travel Agent complain dengan Pihak Café.

b) Terjadinya persaingan harga antar Café yang menyebabkan Travel Agent berpaling ke lain Café.

c) Jika dilihat dari aksesnya menuju Café pada saat jam operasional lumayan macet yang menyebabkan kenyamanan tamu atau wisatawan menjadi terganggu

d) Pembayaran yang dilakukan Travel Agent biasanya menggunakan invoice dan akan dibayarkan sebulan kemudian bahkan lebih. Ini dapat mengganggu kelancaran keuangan dari kas Café.

e) Sulitnya pihak café untuk menaikkan harga paket karena persaingan yang sangat ketat

3. Opportunity ( peluang )

Tentunya terdapat peluang yang menyebabakan kerja sama ini bisa terjadi. Peluang tersebut dapat diuraikan sebagai berikut :

a) Adanya keindahan pantai yang dimiliki pantai kedonganan yang bisa menjadikan Kedonganan menjadi wisata kuliner. Seperti : pantainya yang berpasir putih, keindahan sutsetnta, wisatawan juga dapat melihat aktivitas nelayan serta pada malam hari aktivitas penerbangan Airport Ngurah Rai sangat indah untuk dilihat.

b) Kerja sama ini terjadi karena lokasi Kedonganan yang memang sangat strategis untuk masuk di dalam tour paket wisatawan khususnya seperti Uluwatu Tour yang menjadikan Café
Kedonganan menjadi tujuan terakhir untuk menikmati makan malam

c) Melihat peluang tersebut, pihak Café mempunyai ide untuk menjalin kerja sama dengan Travel Agent untuk lebih menigkatkan kunjungan tamu ke Café mereka.

d) Serta dari pihak desa Kedonganan juga sangat mendukung dari kerja sama ini karena dapat memberikan efek yang baik bagi Desa Kedonganan serta perekonomian masyarakat desa yang meningkat dari aktivitas wisata yang terjadi

4. Threat ( ancaman)

a) Karena persaingan harga yang sangat ketat, sering terjadi perubahan harga paket sesuai permintaan Travel Agent. Ini bisa merugikan pihak Café karena keuntungan yang mereka dapat sedikit

b) Pemutusan kerja sama secara sepihak oleh Travel Agent dapat terjadi karena mendapat harga paket yang lebih murah dari Café lain

c) Kebersihan pantai harus diperhatikan karena ini berpengaruh terhadap citra Kedonganan di mata tamu atau wisatawan khususnya pada musim hujan sampah kiriman datang dan dapat mengotori bibir pantai

d) Jika persaingan harga antar Café tidak sehat maka di khawatirkan akan menurunkan tingkat pendapatan Café karena hanya mendapatkan keuntungan yang sedikit.

\section{SIMPULAN DAN SARAN Simpulan}

Sistem kerja sama antara Café Kedonganan dan Travel Agent menimbulkan beberapa dampak yang terjadi dari faktor internal maupun eksternal. Melalui analisis pendekatan SWOT yaitu telah dilakukan penelitian terhadap kekuatan (Strenghts), kelemahan (Weakness), peluang (Opportunities) dan ancaman (Threat) diperoleh kesimpulan :

1. Strategi SO terhadap kerja sama yang terjadi :

Desa Kedonganan dikenal sebagai tempat menjual makanan seafood oleh wisatawan (S), dari hal tersebut café 
Kedonganan memanfaatkan peluang serta Travel Agent juga melihat peluang tersebut dan terjadilah kerja sama tersebut $(\mathrm{O})$

2. Strategi ST terhadap kerja sama yang terjadi :

Dengan adanya kerja sama, maka kedua belah pihak telah menyepakati hargaharga paket makanan sesuai kontrak perjanjian (S), karena banyaknya café yang ada maka persaingan harga dapat mengancam kerja sama tersebut akan terhenti (T)

3. Strategi WO terhadap kerja sama yang terjadi :

Dalam kerja sama tersebut ada keluhankeluhan yang disampaikan oleh Travel Agent kepada Café bahwa tamu atau wisatawan tidak mendapatkan pelayanan yang terbaik (W), tetapi itu bisa menjadikan suatu peluang untuk menerima keluhan tersebut dan mencoba untuk memberikan pelayanan yang lebih baik lagi agar kerjasama yang dilakukan berjalan lancar (O)

4. Strategi WT

Adanya persaingan yang tidak sehat di dalam masalah harga membuat cafécafé di Kedonganan melakukan kerjasama dengan Travel Agent melalui keuntungan-keuntungan yang tidak sehat (W), ini bisa membuat suatu perang harga yang tidak sehat dan mengancam kestabilan harga produk yang telah disepakati sebelumnya (T)

\section{Saran}

Berdasarkan hasil pembahasan, maka dapat diberikan saran yang dianggap perlu untuk kemajuan serta kelancaran system kerja sama Travel Agent dengan Café di Kedonganan yakni :

1. Sebaiknya di dalam melakukan kerja sama, sebelumnya melakukan perjanjian yang telah disepakati bersama agar ada peraturan yang mengatur kedua belah pihak

2. Sebaiknya seluruh pengelola café mengadakan rapat bersama untuk menetapkan harga seafood alacarte maupun paket untuk Travel Agent agar tidak terjadinya persaingan yang tidak sehat.

3. Pihak café juga harus memberikan pelayanan yang terbaik kepada tamu atau wisatawan yang datang dengan sendirinya maupun melalui Travel Agent. Karena dengan memberikan pelayanan yang maksimal akan memberikan dampak yang positif serta menimbulkan kepercayaan dari pihak Travel Agent dengan terus membawa tamu mereka ke café tersebut.

4. Pihak café harus memberikan pelatihan mengenai kinerja karyawan tentang bagaimana memberikan pelayanan yang maksimal kepada tamu. Agar tamu merasa puas dengan pelayanan yang diberikan.

5. Agar pihak café beserta semua yang terlibat untuk memperlihatkan kebersihan area café dan pantai kedonganan agar tetap bersih dan indah.

6. Agar memberikan guest comment kepada tamu yang selesai menikmati hidangan makanan. Untuk mengetahui kekurangan yang harus segera diperbaiki.

\section{DAFTAR PUSTAKA}

Anonim. 2006. Direktori 2006. Denpasar. Asiyethana, I Putu. 2010. "Peranan Desa Adat Dalam Pengelolaan Industri Café Di Sentra Pariwisata Pantai Kedonganan Kabupaten Badung”. Denpasar: Program Studi Pariwisata Universitas Udayana

Darmadjati, R.S. 1995. Istilah-istilah Dunia Pariwisata. Jakarta : Pradnyamita

Dinas Pariwisata Provinsi Bali

Fathansyah,Ir. 2002. Basis Data. Bandung : Informatika.

Indrajit. 2001. Analisis dan Perancangan Sistem Berorientasi Object. Bandung : Informatika.

Jogianto HM. 2005. Sistem Teknologi Informasi. Andi. Yogyakarta

Kesrul, M. 2003. Penyelenggara Operasional Perjalanan Wisata. Jakarta : PT. Grasindo

Kusmayadi. 2002. Metodologi Penelitian 
Vol. 3 No. 2, 2015

dalam Bidang Kepariwisataan. Jakarta: PT. Gramedia Pustaka Utama

Marpaung, Happy. 2002. Pengetahuan Kepariwisataan. Bandung: Alfabeta Rangkuti, Freddy. 2002. Analisis SWOT Teknik Membedah Kasus Bisnis. Jakarta: Gramedia Pustaka Utama.

Robert, Murdick. 1991. Sistem Informasi Untuk Manajemen Modern. Jakarta : Erlangga.

Wahyu, Adi. 2010. "Pengelolaan Dan Strategi Pemasaran Daerah Pantai Kedonganan Sebagai daerah Tujuan Wisata Kuliner Seafood Di

Kecamatan Kuta, Kabupaten Badung “. Denpasar: Program Studi Pariwisata Universitas Udayana.

Yoeti, Oka A. 1993. Pengantar

Pariwisata. Jakarta: Angkasa 